\title{
Central Connections of the Lacrimal Functional Unit
}

Catherine Willshire ${ }^{1}$ BSc (Hons), Roger J Buckley ${ }^{1}$ FRCS FRCOphth HonFCOptom and Anthony J Bron $^{1,2}$ FRCOphth FMedSci FARVO

${ }^{1}$ Vision and Eye Research Unit, Anglia Ruskin University, Cambridge UK, ${ }^{2}$ Nuffield Department of Clinical Neurosciences and Nuffield Laboratory of Ophthalmology, University of Oxford, UK

Postal address of corresponding author: YST213, Vision and Eye Research Unit, Faculty of Medical Science, Anglia Ruskin University, Cambridge, CB1 2LZ, UK.

E-mail address: clw181@sstudent.anglia.ac.uk

Telephone: +447736327405

Keywords: Cross-innervation, Lacrimal Functional Unit, Reflex Tear Response

There are no conflicts of interest.

The authors alone are responsible for the content and writing of the paper.

Disclosures in relation to this study: C. Willshire, None; R.J. Buckley, None; A.J. Bron, None. 


\section{ABSTRACT}

Purpose To study the contribution of each eye to the reflex tear response, after unilateral and bilateral topical anaesthesia.

Method A closed eye, modified Schirmer test was performed bilaterally in 8 normal subjects, in a controlled environment chamber set to $23^{\circ} \mathrm{C}, 45 \%$ relative humidity and $0.08 \mathrm{~m} / \mathrm{s}$ airflow. Eye drops were instilled into each eye 10 minutes before the Schirmer test. Experiments were: a) bilateral saline (control) b) unilateral anaesthesia (ipsilateral anaesthetic; contralateral saline) and c) bilateral anaesthesia.

$\underline{\text { Results }}$ There was no difference in between-eye wetting lengths in the saline control eyes $(p=0.394)$ or the bilaterally anaesthetised eyes $(p=0.171)$. Wetting length was reduced in both eyes after bilateral anaesthesia compared to saline controls $(p=0.001 ; p=<0.0005)$. After unilateral anaesthesia, wetting length was reduced in the anaesthetised eye compared to its saline control by $51.4 \%(p=<0.0005)$ and compared to its fellow, unanaesthetised eye $(p=0.005)$. The fellow eye value was also reduced compared to its saline control $(p=0.06)$. Conclusions Wetting length was reduced by topical anaesthesia, when instilled bilaterally and ipsilaterally. The latter response implies an ipsilateral, reflex sensory drive to lacrimal secretion. In the unanaesthetised fellow eye the reduction compared to its saline control was not quite significant. This implies a relative lack of central, sensory, reflex cross-innervation, although the possibility cannot entirely be ruled out. These results are relevant to the possibility of reflex lacrimal compensation from a normal, fellow eye, in cases of unilateral corneal anaesthesia. 


\section{INTRODUCTION}

Tear secretion is finely adjusted in response to environmental conditions by a neural reflex that is driven by trigeminal afferents from the ocular surface. The ocular surface, its secretory appendages and the reflex pathway that connects them are referred to as the Lacrimal Functional Unit (LFU). ${ }^{1}$ When the eyes are open and exposed to a variety of stresses (low humidity, wind, cold and other physical or chemical agents), the reflex pathway adjusts lacrimal secretion in proportion to the stress. This homeostatic mechanism is regulated particularly, by sensory inputs from the cornea, which receives a rich sensory innervation, ${ }^{2}$ and ensures that a stable tear film moistens the ocular surface at all times. The nasal mucosa has also been found to provide major sensory inputs that influence lacrimal secretion. ${ }^{3,4}$

The lacrimal and accessory lacrimal glands receive both parasympathetic and sympathetic innervation. ${ }^{5}$ The afferent (sensory) limb of the reflex arc originates in the cornea and travels via the ophthalmic branch of the trigeminal nerve (Vth cranial nerve), to the pons, where central endings synapse with neurons of the superior salivatory nucleus (SSN). ${ }^{1}$ This sensory input is then processed in the SSN along with inputs from other locations, to produce a graded output. ${ }^{6}$

The parasympathetic, efferent limb of the reflex arc arises in the SSN and projects to the lacrimal and meibomian glands and to the goblet cells of the conjunctival epithelium after synapsing with third order fibres in the pterygopalatine ganglion. These third order parasympathetic neurons arise in the ipsilateral pterygopalatine ganglion; in the monkey a small input arises from the contralateral ganglion ${ }^{7}$ but the existence of such a source in the human is not known.

There are various other inputs to the lacrimal gland that act via the SSN in conjunction with the cornea; nasal mucosa, skin (not only pain but also including lid margin and ciliary/lash 'tickle'), retina (bright lights), acute pain and emotional stimuli, that not only influence lacrimal secretion from moment to moment but also determine the responsiveness of the gland to other sensory stimuli (Figure 2). Ocular anaesthesia can result 
from damage to the ophthalmic division of the trigeminal nerve anywhere along its course from varying causes, such as viral infection, chemical trauma and physical injury, including corneal surgery. Corneal anaesthesia is regularly induced by refractive surgery such as PRK or LASIK, ${ }^{8-11}$ or may be caused by compression of the trigeminal nerve or ganglion. ${ }^{12}$ A decrease in sensory nerve function can also be caused by systemic disorders such as diabetes or multiple sclerosis. ${ }^{13}$ Bilateral topical anaesthesia has been shown to reduce but not abolish lacrimal secretion in both eyes, measured by the Schirmer I test ${ }^{14-16}$ or by fluorophotometry ${ }^{15}$ and similarly, unilateral trigeminal anaesthesia, as caused by herpes simplex keratitis, is accompanied by an ipsilateral reduction in reflex tear secretion, of a degree dependent on the level of sensory loss on the affected side. ${ }^{17,18}$ Additionally, a lesser fall in the reflex tear response occurs in the unaffected eye.

This raises the question as to whether the sensory drive from a fellow, normal eye can compensate for and limit the risk of dry eye on the anaesthetised side. In particular, the nature of any sensory input from a normal cornea to the contralateral SSN is not known and hence its potential to influence contralateral lacrimal gland secretion is uncertain.

In order to explore this, an experiment was designed to study the relative contribution of each eye to the reflex tear response, measured by a modified Schirmer I test (see methods) in controlled room conditions, after unilateral and bilateral topical anaesthesia.

\section{MATERIALS AND METHODS}

\section{Subjects}

Eight subjects with normal eyes were recruited, three male and five female, aged 23.1 years \pm 4.3 (mean \pm SD) from students and staff at Anglia Ruskin University. Participants were individuals with a normal ocular surface by history and examination, according to defined criteria. Following a preliminary visit subjects were screened for the following inclusion criteria: tear osmolarity $<308 \mathrm{mOsm} / \mathrm{L} ;{ }^{19}$ OSDI score $<20$; TBUT $>10$ seconds and corneal staining < grade 2 using the Oxford clinical grading scale. ${ }^{20}$ Subjects were excluded if they had any 
active ocular disease, any clinically significant lid or conjunctival abnormalities (corneal scars or opacities), any clinically significant limbal or bulbar injection or conjunctival staining, any eye surgery or injury within the previous 6 months, any systemic disease affecting ocular health, had nasolacrimal occlusion or were using any topical medications. Subjects were instructed not to use ocular cosmetics on the day of assessment and, if a contact lens wearer, not to use their lenses for at least 8 hours before the procedure.

\section{Ethical approval}

Studies were performed according to the Declaration of Helsinki. Ethical approval was obtained from the Research Ethics Committee of Anglia Ruskin University and National Research Ethics Service Committee (South East Coast-Brighton and Sussex). Written consent was obtained from all participants following a verbal and written explanation of the study procedures.

\section{Controlled Environment Chamber}

Studies were carried out in a PSR 'B' Series, Weiss Gallenkamp, controlled environment chamber (CEC), in which temperature, humidity and wind speed can be standardised. The CEC consists of a small chamber, with internal dimensions of $2.13 \mathrm{~m} \times 3.15 \mathrm{~m} \times 2.04 \mathrm{~m}$, in which two subjects and one examiner can be housed comfortably, together with additional investigational equipment. The air in the CEC circulates constantly with a laminar flow of $0.08 \mathrm{~m} / \mathrm{s}$ and temperature can be altered between $+5^{\circ} \mathrm{C}$ and $+40^{\circ} \mathrm{C}$ with a fluctuation range of $+/-2^{\circ} \mathrm{C}$, and relative humidity between $5 \%\left(\right.$ at $\left.10^{\circ} \mathrm{C}\right)$ and $70 \%\left(\right.$ at $\left.40^{\circ} \mathrm{C}\right)$ with a fluctuation range of $+/-3 \%$. Environmental conditions within the chamber can be monitored throughout the period of examination. In preliminary studies it was found that, following the entry of subjects into the chamber, a period of up to 10 minutes was required for the CEC conditions to be restored to their set values. Therefore a period of 10 minutes after entry was allowed for CEC equilibration before commencement of data collection.

In this study experiments were conducted in controlled 'standard room conditions' based on guidelines contained in the ${ }^{21,22}$ at $23^{\circ} \mathrm{C}, 45 \%$ relative humidity and $0.08 \mathrm{~m} / \mathrm{s}$ airflow. 


\section{Schirmer test measurement}

In brief, the Schirmer test I without anaesthesia is considered to measure the reflex response of the lacrimal gland to ocular surface stimulation, acting via the LFU. ${ }^{23}$ This is therefore a measure of lacrimal secretory potential assuming that the sensory and motor elements of the reflex apparatus are intact. We refer to this as the reflex Schirmer test in this report. The Schirmer I test can also be performed after instilling a topical anaesthetic, in which case, when it is performed bilaterally, in resting environmental conditions, it reflects the constitutive secretory activity of the lacrimal glands, modified by non-ocular inputs, sometimes referred to as basal tear secretion. ${ }^{24}$ We refer to this, here, as the Schirmer test with anaesthesia.

In the current study each subject underwent the Schirmer I test following topical anaesthesia bilaterally, and the Schirmer I test bilaterally, without anaesthesia, but preceded by instillation of saline drops as a control for the instillation of anaesthetic drops in the previous study. A further Schirmer I test was performed, with one eye receiving topical anaesthetic and the other, saline.

Since the instillation of a topical anesthetic induces reflex tearing and the instilled volume itself could contribute to wetting of the Schirmer strip, ${ }^{25,26}$ the test is usually performed after removal of excess fluid from the conjunctival sac with an absorbent tissue. In the present study, however, whether the Schirmer I test was conducted with anaesthesia or with saline, removal of excess fluid from the conjunctival sac (as opposed to the eyelid skin) was not employed, because of the uncertainty of the adequacy of removal and to avoid the effects of lid manipulations on tear production. ${ }^{27}$ Instead, ten minutes were allowed to elapse between drop instillation and performance of the test, on the basis that, in the presence of spontaneous blinking, excess fluid will be drained away over this period. This strategy is supported by the study of Bandlitz et al ${ }^{28}$ which showed that meniscus curvature, a measure of tear volume $e^{29}$ was restored to normal within 5 minutes of instillation of a drop of an artificial tear solution containing hydroxypropyl-guar and glycol. Our protocol involved instilling one drop of either a topical anaesthetic or of saline (Minims $\left.{ }^{\circledR}\right)$ followed by another drop 30 seconds later. The average volume of each eye drop instilled was: saline $41 \mu \mathrm{l}$, tetracaine $34 \mu \mathrm{l}$ and proxymetacaine $41 \mu \mathrm{l}$. Using 
fluorophotometry, Mishima et $\mathrm{al}^{30}$ determined that the average tear volume present in the eye was $6.2 \mu \mathrm{l} \pm 2.0$ and that the maximum capacity of the cul-de-sac for added volume was $30 \mu \mathrm{l}$; any fluid above this level was observed to overflow. In this study any overflow of fluid was dabbed away by the examiner, using a tissue applied to the lid margins and canthi whilst the eyes were closed.

Following the instillation of eye drops and allowing 10 minutes for drainage, the closed-eye, ${ }^{31}$ modified Schirmer test (see below) was then performed in both eyes of each subject. A Schirmer strip was hooked over the lid margin at its lateral third in the right, then the left eye, and the wetting length was recorded 5 minutes after the moment of insertion, for each eye. If full wetting occurred within the 5 minutes the time at which this occurred was noted.

\section{The modified Schirmer Test using a sheathed Schirmer strip}

Schirmer strips were modified by enclosing them in plastic pockets in order to minimise water loss from their surfaces during the test and to free the test from dependence on ambient conditions, of relative humidity, airflow and temperature. ${ }^{32,33}$ Calibrated Schirmer strips, (Whatman quantitative filter paper No. 41, Biotech ${ }^{\circledR}$ ) were used in all experiments (Figure 3). Sheaths were constructed from water impermeable plastic sheeting (ImageLast laminating pouch, Fellowes ${ }^{\circledR}$ ) of 80 microns thickness, by placing two large sheets in apposition and heat-sealing (BaByliss ${ }^{\circledR}$ hair straightening irons) the sides of a narrow rectangle that was cut to $40 \mathrm{~mm}$ x $20 \mathrm{~mm}$ and formed a pocket to house the Schirmer strip. The Schirmer strip was slipped into place just prior to use, after first folding the tip for insertion over the lateral third of the lid margin (Figure 3). When the sheathed Schirmer strip was in place for measurement of reflex tearing, its presence was generally indistinguishable by the subject from an unsheathed strip. The Schirmer strip was removed from the sheath for measuring.

\section{Instillation of eye drops}

For topical anaesthesia, a procedure was adopted to achieve the minimum reflex tearing and the densest level of anaesthesia with the anaesthetics used. A single drop of the short-acting anaesthetic $0.5 \%$ Proxymetacaine 
(Minims ${ }^{\circledR}$ ) was instilled first; this drop stings only slightly. This was followed, 30 seconds later, by one drop of 1\% Tetracaine $\left(\right.$ Minims $\left.{ }^{\circledR}\right)$. This drop would normally sting markedly when instilled into an unanaesthetised eye but provides an increased density of anaesthesia. ${ }^{15,34}$ Instillation into the eye already anaesthetised by proxymetacaine induced no additional reflex tearing. ${ }^{24}$ To maximise spreading and mixing of the drops, the subject was asked to look up while each drop was instilled into the lower fornix and then asked to blink with the lower lid still drawn downwards; this distributes the drop without overflow. ${ }^{35}$ Finally, the eyes were closed to allow excess fluid to be dabbed away from the lid margins and canthi (but not from the conjunctival sac). This sequence was followed by a period of 10 minutes of spontaneous blinking prior to any experimental procedure. This is in keeping with the approach of $\mathrm{Xu}$ and Tsubota $^{36}$ who performed the anaesthetic Schirmer test at an interval of five minutes after drop instillation and without prior removal of tear fluid from the conjunctival sac. The same protocol was adopted for the instillation of saline.

\section{Outline of visits}

Subjects made two visits on separate days (Figure 1). At each visit, either saline or topical anaesthetic eye drops were instilled into each eye.

The first visit lasted approximately one hour. The subject and the examiner entered the CEC and saline was instilled in both eyes as per the protocol, followed by a Schirmer test. Following this the examiner and subject remained in the CEC for a 10 minute recovery period. This recovery period was over three times longer than that considered sufficient for the eye to recover after multiple Schirmer tests in the Loran et $\mathrm{al}^{37} \mathrm{study}$. It was randomly decided whether the subject would then undergo the unilateral or bilateral afferent blockade experiment, and the protocol for instillation of the appropriate eye drops was repeated.

The second visit occurred on a subsequent day and lasted approximately 30 minutes. After entering the CEC the subject received either unilateral or bilateral anaesthesia depending on which regime had been undertaken at the previous visit. 
A slit-lamp examination was carried out following all procedures to check for adverse events.

\section{Statistical Analysis}

The differences in Schirmer wetting lengths when compared across the three conditions were analysed using a repeated measures ANOVA with contrasts. The Bonferroni method was used to make adjustments for multiple comparisons. The differences in Schirmer wetting lengths within the individual conditions were analysed using a paired t-test. Shapiro-Wilk test was used to evaluate normality of distribution. Differences were considered statistically significant with $P$ values less than 0.05 . Data is presented as mean \pm standard deviation. Analyses were performed using SPSS 2.0.

\section{RESULTS}

To facilitate data presentation, the eye which had received anaesthesia in the unilateral experiment was designated Eye 1 and the fellow eye was designated Eye 2, throughout the study. The Schirmer wetting test scores for all eight participants in each phase of the experiment are presented in Table 1 and Figure 4.

There was no significant difference in between-eye wetting lengths in the saline control eyes: $1.75 \mathrm{~mm} \pm 5.44$ ( $p$ $=0.394)$, or in the bilaterally anaesthetised eyes: $1.31 \mathrm{~mm} \pm 2.43(p=0.171)$. Bilateral topical anaesthesia reduced lacrimal secretion by $62.4 \%$ from the control value in Eye $1(23.13 \mathrm{~mm} \pm 7.22$ to $8.69 \mathrm{~mm} \pm 5.20)$ and by $59.8 \%$ from the control value in Eye $2(24.88 \mathrm{~mm} \pm 4.12$ to $10.00 \mathrm{~mm} \pm 3.78)$, an average decrease in Schirmer wetting length of $61.1 \%$.

In the unilateral anaesthesia experiment, the wetting length was reduced by $51.4 \%$ in the anaesthetised eye compared to its saline control eye i.e. by $11.88 \mathrm{~mm} \pm 3.98(23.13 \mathrm{~mm} \pm 7.22$ to $11.25 \mathrm{~mm} \pm 4.13, p=<0.0005)$. It was also reduced compared to its fellow eye by $8.13 \mathrm{~mm} \pm 5.62(19.38 \mathrm{~mm} \pm 7.39$ to $11.25 \mathrm{~mm} \pm 4.13, p=0.005)$. The fellow eye response was also reduced compared to its saline control by $5.5 \mathrm{~mm} \pm 5.71(24.88 \mathrm{~mm} \pm 4.12$ to $19.38 \mathrm{~mm} \pm 7.39)$; however, this did not reach significance $(p=0.06)$. 
Bilateral topical anaesthesia reduced the Schirmer wetting length further than that measured in the unilateral anaesthetic condition by $2.6 \mathrm{~mm} \pm 5.12(11.25 \mathrm{~mm} \pm 4.13$ to $8.69 \pm 5.20)$, but this also did not reach significance $(p=0.60)$

No adverse corneal events were recorded following each experiment.

\section{DISCUSSION}

The focus of this study has been to determine whether, in humans, there is sensory cross-connectivity between the cornea of one side and the opposite SSN. It is a familiar experience that a foreign body in one eye can induce tearing from both eyes. Is this due to sensory cross-connectivity of the kind discussed here, or is it mediated via pain pathways? The same can be asked concerning irritation of the nasal mucosa, where, when performing the nasolacrimal Schirmer II test, the response of both eyes is recorded following stimulation of the nasal mucosa on one side only. ${ }^{38}$

In the present study we confirmed, as in other reports that bilateral topical anaesthesia results in a bilateral reduction of the Schirmer wetting length compared to the reflex Schirmer response in control eyes. ${ }^{10,14,15,24,39}$ We also found that unilateral topical anaesthesia resulted in an ipsilateral reduction of Schirmer wetting of similar degree. These results can be interpreted as due to the withdrawal of the reflex sensory drive from the ocular surface to the ipsilateral SSN and lacrimal gland. However, some interpretative caution must be exercised, since instilled anaesthetic drops, draining into the nasolacrimal duct, are likely to cause some degree of anaesthesia of the nasal mucosa in the floor of the nasal cavity, and the study of Gupta et $\mathrm{al}^{4}$ indicated that nasal anaesthesia alone can inhibit lacrimal secretion. The possibility therefore arises that some of the effect of topical ocular anaesthesia on lacrimal secretion could be due to a loss of sensory drive from the nose.

Heigle and Pflugfelder ${ }^{3}$ demonstrated an ipsilateral reduction in the reflex Schirmer response of 90.8\%, compared to normal controls, in patients with unilateral neurotrophic keratitis $(\mathrm{NK})$ in whom nasal mucosal anaesthesia was combined with dense corneal anaesthesia. This contrasted with the findings in 4 patients with 
Herpes zoster ophthalmicus (HZO) without keratitis, in whom, although there was moderate reduction in corneal sensitivity, nasal sensation was normal and there was no reduction in the reflex Schirmer response with or without nasolacrimal stimulation. They concluded that there was an ipsilateral, sensory stimulus to lacrimal secretion arising from the nasal mucosa. These authors also showed that the Schirmer wetting length was reduced by $60.7 \%$ in the contralateral eyes of those patients with NK, which they considered to be evidence of sensory cross-innervation from the nasal mucosa of one side to the SSN of the opposite side, although it could not be excluded that the original or activated infection had caused subclinical nerve damage on the clinically unaffected side.

This was supported by a further study, in which Schirmer wetting length, compared to baseline, was reduced to a similar degree on both sides, following unilateral nasal anaesthesia $(36.4 \%$ on the ipsilateral and $29.7 \%$ on the contralateral side). ${ }^{4}$ These authors concluded that sensory stimulation of the nasal mucosa was an important contributor to basal tear production. Since the effects were demonstrated using the reflex Schirmer I test, which is not relevant to basal tear secretion, we would rather conclude that this study provided evidence for a modulatory influence of nasal sensory input on the reflex tear response, with evidence of cross-innervation.

The existence of sensory cross-innervation is relevant to the health of the fellow eye in conditions that affect the sensory innervation of the ocular surface unilaterally, such as unilateral refractive surgery, Herpes simplex keratitis (HSK), HZO and in NK from whatever cause. The aim of the present study was to explore the contribution of each eye to the reflex Schirmer response of its fellow eye, measured after unilateral and bilateral topical anaesthesia. We hypothesised that, in the steady state, when the eyes are open and exposed to the environment, sensory inputs from each eye stimulate lacrimal secretion both ipsilaterally and contralaterally, via central connections of the trigeminal nerve with the SSN on each side. We refer to this arrangement, here, as sensory cross-innervation. This sensory drive would be concerned with maintaining a steady state in a given environment, and by withdrawing one of the major sensory inputs through corneal topical anaesthesia we hoped 
to investigate how the output would be modified. There is evidence for contralateral, central trigeminal projections in animals but this cannot be taken as supportive for such a condition in humans., ${ }^{70-42}$

If there were a significant level of central, sensory cross-innervation then we would predict that when the Schirmer test was performed simultaneously in the two eyes, with one eye anaesthetised and the other not, the fall in reflex secretion on the anaesthetised eye would be offset by an afferent drive from the unanaesthetised fellow eye and conversely, in the unanaesthetised eye, the reflex response would be reduced, owing to a lack of drive from the now anaesthetised fellow eye. Our results demonstrated a reduction in Schirmer wetting length following bilateral topical anaesthesia, averaged for the two eyes, of $61.1 \%$ (Table 1). This compares with a reduction of the Schirmer response of between $28-53 \%$ reported in the literature. . $^{10,14-16}$

Following unilateral topical anaesthesia in our study, the effects on the Schirmer wetting length were in the direction predicted by an assumption that there is sensory cross-innervation to the SSN, i.e. the fall in secretion in the anaesthetised eye was less than that which occurred when there was bilateral anaesthesia and the wetting length in the fellow, unanaesthetised, eye was lower than in its control eye following the bilateral Schirmer test, after saline. However, the differences shown in each case were not significant $(p=0.60 ; p=0.06)$. Because the numbers were small, we feel that this does not entirely exclude the existence of sensory cross-innervation and the possibility that topical anaesthetics may induce a degree of nasal mucosal anaesthesia which could itself reduce the secretory drive to the lacrimal gland of a fellow eye, could weigh further against the existence of cross-innervation from the cornea to the contralateral SSN.

A number of studies in the literature could be interpreted as supportive of cross-innervation. Several investigators have reported a bilateral reduction in the reflex Schirmer response in the presence of unilateral HSK, noting that the diminished response in the fellow eye was often not significantly different from that in the affected eye. ${ }^{17,18,43}$

However, there is evidence that in both HSK and HZO, unilateral clinical disease is accompanied by a contralateral loss of trigeminal innervation of the clinically unaffected cornea. The Hamrah group have 
compared clinical indices in the affected and unaffected eyes of 25 patients with unilateral $\mathrm{HSK}^{44}$ and 27 patients with unilateral $\mathrm{HZO}$ with those in healthy controls. ${ }^{45}$ In each condition, they demonstrated a significant decrease in a range of sub-basal nerve parameters, not only in the affected eye but also, to a lesser degree, in the clinically unaffected eye. These observations are consistent with findings in patients with Herpes zoster infections at other sites in the body. ${ }^{46,47}$ Whatever the basis for the involvement of contralateral sensory neurones following clinically unilateral Herpes simplex or Herpes zoster infections it means that the finding of a reduced contralateral Schirmer response in such conditions cannot be interpreted as evidence for sensory crossinnervation in the ophthalmic division of the trigeminal nerve.

However, the influence of trigeminal sensory deprivation confined to a single cornea, on the reflex Schirmer response, can be examined in another clinical scenario. Various forms of refractive surgery (e.g. PRK and LASIK) cause a loss of corneal sensitivity for a period of $6-12$ months after the procedure ${ }^{8-10,48}$ and a small number of studies have demonstrated a reduction in the reflex Schirmer response following such procedures. In healthy individuals, in whom the lacrimal glands and the neural pathways of the LFU may be assumed to be intact, any effect of such surgery on the ipsilateral reflex Schirmer response may be interpreted as due to a blockade of the afferent limb of the LFU on the side of the surgery. See Table 2 for a summary of the results for the above studies.

These various reports give confidence to the view that, in human subjects, corneal anaesthesia alone leads to an ipsilateral reduction of lacrimal secretion by decreasing the sensory drive from the cornea to the ipsilateral lacrimal gland, independent of any action on the nasal mucosa. There is also a suggestion of a graded response to corneal anaesthesia, since in one study comparing ReLEx (lenticule extraction using femtosecond laser) surgery, with LASIK, the effect of surgery on corneal sensitivity was smaller in the former procedure and the reduction of the reflex Schirmer response was less. ${ }^{11}$ Similarly in studies of LASIK surgery, a reduction in Schirmer wetting length was further reduced following an anaesthetic Schirmer test, suggesting that refractive surgery does not cause complete corneal anaesthesia and the effect can be fortified by the addition of topical 
anaesthesia. ${ }^{10,39}$ Here, however, as noted, we cannot exclude an effect due to a degree of coincident, nasal anaesthesia.

Overall we concur with the general proposition of Heigle and Pflugfelder" that, "Perhaps lacrimal gland stimulation results from the sum of sensory inputs from the adnexal skin, cornea, nasal mucosa, contralateral eye and even central stimulation", although the current study suggests that, if there is an input from the contralateral ocular surface, it is limited compared to that from the contralateral nasal mucosa.

The effects of inputs which maintain lacrimal secretion in non-stressful environmental conditions, should be distinguished from those that occur in more extreme environmental conditions such as exposure to noxious chemical and physical stimuli, when it may be supposed that additional pathways are recruited.

It is still of great importance to discover more about the afferent sensory connections to the SSN from one eye to the efferent lacrimal output of the fellow eye, as there are many clinical situations that result in unilateral anaesthesia, and further research is planned with expanded subject numbers to attempt to clarify the concept of cross-connectivity.

\section{REFERENCES}

1. Stern ME, Gao J, Siemasko KF, Beuerman RW, Pflugfelder SC. The role of the lacrimal functional unit in the pathophysiology of dry eye. Exp Eye Res. 2004;78(3):409-416.

2. Müller LJ, Marfurt CF, Kruse F, Tervo TM. Corneal nerves: Structure, contents and function. Exp Eye Res. 2003;76(5):521-542.

3. Heigle TJ, Pflugfelder SC. Aqueous tear production in patients with neurotrophic keratitis. Cornea. 1996;15(2):135-138. 
4. Gupta A, Heigle T, Pflugfelder SC. Nasolacrimal stimulation of aqueous tear production. Cornea. 1997;16(6):645-648.

5. Dartt DA, Willcox MD. Complexity of the tear film: Importance in homeostasis and dysfunction during disease. Exp Eye Res. 2013;117:1-3.

6. Meng ID, Kurose M. The role of corneal afferent neurons in regulating tears under normal and dry eye conditions. Exp Eye Res. 2013(0):1-9.

7. van der Werf F, Baljet B, Prins M, Otto JA. Innervation of the lacrimal gland in the cynomolgous monkey: A retrograde tracing study. J Anat. 1996;188 ( Pt 3)(Pt 3):591-601.

8. Özdamar A, Aras C, Karakas N, Sener B, Karacorlu M. Changes in tear flow and tear film stability after photorefractive keratectomy. Cornea. 1999;18(4):437-439.

9. Aras C, Ozdamar A, Bahcecioglu H, Karacorlu M, Sener B, Ozkan S. Decreased tear secretion after laser in situ keratomileusis for high myopia. Journal of Refractive Surgery. 2000;16(3):362-364.

10. Siganos DS, Popescu CN, Siganos CS, Pistola G. Tear secretion following excimer laser in situ keratomileusis. Journal of Refractive Surgery. 2002;18(2):124-126.

11. Gao S, Li S, Liu L, et al. Early changes in ocular surface and tear inflammatory mediators after small-incision lenticule extraction and femtosecond laser-assisted laser in situ keratomileusis. PloS one. 2014;9(9):e107370.

12. Puca A, Meglio M, Vari R, Tamburrini G, Tancredi A. Evaluation of fifth nerve dysfunction in 136 patients with middle and posterior cranial fossae tumors. Eur Neurol. 1995;35(1):33-37.

13. Bonini S, Rama P, Olzi D, Lambiase A. Neurotrophic keratitis. Eye. 2003;17(8):989-995. 
14. Lamberts DW, Foster CS, Perry HD. Schirmer test after topical anesthesia and the tear meniscus height in normal eyes. Arch Ophthalmol. 1979;97(6):1082-1085.

15. Jordan A, Baum J. Basic tear flow. does it exist? Ophthalmology. 1980;87(9):920-930.

16. Li N, Deng X, He M. Comparison of the schirmer I test with and without topical anesthesia for diagnosing dry eye. International journal of ophthalmology. 2012;5(4):478.

17. Simard-Lebrun A, Boisjoly H, Al-Saadi A, Choremis J, Mabon M, Chagnon M. Association between unilateral quiescent stromal herpetic keratitis and bilateral dry eyes. Cornea. 2010;29(11):1291-1295.

18. M'Garrech M, Rousseau A, Kaswin G, et al. Impairment of lacrimal secretion in the unaffected fellow eye of patients with recurrent unilateral herpetic keratitis. Ophthalmology. 2013;120(10):1959-1967.

19. Sullivan BD, Whitmer D, Nichols KK, et al. An objective approach to dry eye disease severity. Invest Ophthalmol Vis Sci. 2010;51(12):6125-6130.

20. Bron AJ, Evans VE, Smith JA. Grading of corneal and conjunctival staining in the context of other dry eye tests. Cornea. 2003;22(7):640-650.

21. Anon. Workplace health committee; OHS information sheet no. 5; the working environment Part1-thermal comfort (revised). . 1998.

22. Fang L, Wyon D, Clausen G, Fanger PO. Impact of indoor air temperature and humidity in an office on perceived air quality, SBS symptoms and performance. Indoor Air. 2004;14(s7):74-81.

23. Cho P, Yap M. Schirmer test. I. A review. Optometry \& Vision Science. 1993;70(2):152-156.

24. Jones LT. The lacrimal secretory system and its treatment. Am J Ophthalmol. 1966;62(1):47-60. 
25. Clinch TE, Benedetto DA, Felberg NT, Laibson PR. Schirmer's test: A closer look. Arch Ophthalmol. 1983;101(9):1383-1386.

26. Afonso AA, Monroy D, Stern ME, Feuer WJ, Tseng SC, Pflugfelder SC. Correlation of tear fluorescein clearance and schirmer test scores with ocular irritation symptoms. Ophthalmology. 1999;106(4):803-810.

27. Yokoi N, Komuro A. Non-invasive methods of assessing the tear film. Exp Eye Res. 2004;78(3):399-407.

28. Bandlitz S, Purslow C, Murphy PJ, Pult H. Time course of changes in tear meniscus radius and blink rate after instillation of artificial TearsChanges in tear meniscus radius and blink rate. Invest Ophthalmol Vis Sci. 2014;55(9):5842-5847.

29. Yokoi N, Bron AJ, Tiffany JM, Maruyama K, Komuro A, Kinoshita S. Relationship between tear volume and tear meniscus curvature. Arch Opbthalmol. 2004;122(9):1265-1269.

30. Mishima S, Gasset A, Klyce S, Baum J. Determination of tear volume and tear flow. Invest Ophthalmol Vis Sci. 1966;5(3):264-276.

31. Serin D, Karsloglu S, Kyan A, Alagoz G. A simple approach to the repeatability of the schirmer test without anesthesia: Eyes open or closed? Cornea. 2007;26(8):903-906.

32. Willshire C, Buckley R, Bron A. Standardising the schirmer test by enclosing the strip in a waterproof sheath. Acta Ophthalmol. 2015;93(S255).

33. Buckmaster F, Pearce EI. Effects of humidity on tests of tear production. Cornea. 2016;35(6):754-758.

34. Adriani J, Zepernick R. Clinical effectiveness of drugs used for topical anesthesia. JAMA. 1964;188:711-716.

35. Fraunfelder FT. Extraocular fluid dynamics: How best to apply topical ocular medication. Trans Am Ophthalmol Soc. 1976;74:457-487. 
36. Xu KP, Tsubota K. Correlation of tear clearance rate and fluorophotometric assessment of tear turnover. $\mathrm{Br}$ J Opbthalmol. 1995;79(11):1042-1045.

37. Loran D, French C, Lam S, Papas E. Reliability of the wetting value of tears. Ophthalmic and Physiological Optics. 1987;7(1):53-56.

38. Tsubota K. Tear dynamics and dry eye. Prog Retin Eye Res. 1998;17(4):565-596.

39. Konomi K, Chen L, Tarko RS, et al. Preoperative characteristics and a potential mechanism of chronic dry eye after LASIK. Invest Ophthalmol Vis Sci. 2008;49(1):168-174.

40. Clarke W, Bowsher D. Terminal distribution of primary afferent trigeminal fibers in the rat. Exp Neurol. 1962;6(5):372-383.

41. Pfaller K, Arvidsson J. Central distribution of trigeminal and upper cervical primary afferents in the rat studied by anterograde transport of horseradish peroxidase conjugated to wheat germ agglutinin. J Comp Neurol. 1988;268(1):91-108.

42. Jacquin MF, Chiaia NL, Rhoadest RW. Trigeminal projections to contralateral dorsal horn: Central extent, peripheral origins, and plasticity. Somatosens Mot Res. 1990;7(2):153-183.

43. Keijser S, van Best JA, Van der Lelij A, Jager MJ. Reflex and steady state tears in patients with latent stromal herpetic keratitis. Invest Ophthalmol Vis Sci. 2002;43(1):87-91.

44. Hamrah P, Cruzat A, Dastjerdi MH, et al. Corneal sensation and subbasal nerve alterations in patients with herpes simplex keratitis: An in vivo confocal microscopy study. Ophthalmology. 2010;117(10):1930-1936.

45. Hamrah P, Cruzat A, Dastjerdi MH, et al. Unilateral herpes zoster ophthalmicus results in bilateral corneal nerve alteration: An in vivo confocal microscopy study. Ophthalmology. 2013;120(1):40-47. 
46. Oaklander AL, Romans K, Horasek S, Stocks A, Hauer P, Meyer RA. Unilateral postherpetic neuralgia is associated with bilateral sensory neuron damage. Ann Neurol. 1998;44(5):789-795.

47. Watson C, Deck J, Morshead C, Van der Kooy D, Evans R. Post-herpetic neuralgia: Further post-mortem studies of cases with and without pain. Pain. 1991;44(2):105-117.

48. Battat L, Macri A, Dursun D, Pflugfelder SC. Effects of laser in situ keratomileusis on tear production, clearance, and the ocular surface. Ophthalmology. 2001;108(7):1230-1235. 


\section{FIGURE LEGENDS}

Figure 1. A Timeline outlining the two visits made by subjects on separate days. At each visit, the subject and examiner entered the CEC and either saline or topical anaesthetic eye drops were instilled into each eye. Following a period of 10 minutes for equilibration a modified Schirmer test was then performed in both eyes. At the first visit the bilateral saline protocol was always performed first followed by either the bilateral or unilateral anaesthesia protocol. At the second visit the subject received either the unilateral or the bilateral anaesthesia protocol depending on which regime had been undertaken at the previous visit. A slit-lamp examination was carried out following all procedures to check for adverse events.

Figure 2. A Schematic of the neural reflex arc and possible cross-sensory innervation input from ipsilateral and contralateral afferents resulting in lacrimal gland stimulation. Additional inputs to lacrimal secretion include (clockwise from top left) skin, emotion, nasal mucosa and retina.

Figure 3. A photograph of the unsheathed Schirmer calibrated Schirmer strips, (Whatman quantitative filter paper No. 41, Biotech ${ }^{\circledR}$ ) used in all experiments, and a photograph of the sheathed Schirmer calibrated Schirmer strips, (Whatman quantitative filter paper No. 41, Biotech ${ }^{\circledR}$ ). The Schirmer Sheaths were constructed from water impermeable plastic sheeting (ImageLast laminating pouch, Fellowes ${ }^{\circledR}$ ) of 80 microns thickness, by placing two large sheets in apposition and heat-sealing (BaByliss ${ }^{\circledR}$ hair straightening irons) the sides of a narrow rectangle that was cut to $40 \mathrm{~mm} \times 20 \mathrm{~mm}$ and formed a pocket to house the Schirmer strip. The Schirmer strip was slipped into place just prior to use, after first folding the tip for insertion over the lateral third of the lid margin.

Figure 4. Schirmer wetting test scores for all eight participants, following bilateral saline, unilateral anaesthesia and bilateral anaesthesia phases. To facilitate data presentation, the eye which had received 
anaesthesia in the unilateral experiment was designated Eye 1 and the fellow eye was designated Eye 2. The sign $\neq$ indicates a statistically significant difference from the fellow eye (paired t-test). The sign * indicates a statistically significant difference between Eye 1 or Eye 2 between each experiment (repeat measures ANOVA). Values are mean \pm SD. 


\section{TABLE 2. Summary of raw data}

\begin{tabular}{|c|c|c|c|c|c|c|}
\hline \multirow[t]{3}{*}{ Subject } & \multicolumn{2}{|c|}{$\begin{array}{l}\text { Saline control } \\
n=8\end{array}$} & \multicolumn{2}{|c|}{$\begin{array}{l}\text { Unilateral anaesthesia } \\
n=8\end{array}$} & \multicolumn{2}{|c|}{$\begin{array}{l}\text { Bilateral anaesthesia } \\
n=8\end{array}$} \\
\hline & \multicolumn{6}{|c|}{ Schirmer wetting length $-\mathrm{mm}$} \\
\hline & Eye1 & Eye2 & Eye1 & Eye2 & Eye1 & Eye2 \\
\hline 1 & 33 & 30 & 18 & 25 & 7 & 10 \\
\hline 2 & 24 & 28 & 12 & 15 & 4 & 7 \\
\hline 3 & 16 & 21 & 5 & 15 & 4 & 5 \\
\hline 4 & 15 & 23 & 8 & 12 & 5 & 7 \\
\hline 5 & 17 & 25 & 10 & 23 & 7 & 9 \\
\hline 6 & 20 & 18 & 9 & 15 & 10 & 12 \\
\hline 7 & 28 & 29 & 15 & 34 & 14 & 16 \\
\hline 8 & 32 & 25 & 13 & 16 & 18 & 14 \\
\hline Mean wetting length & $23.1 \pm 7.2$ & $24.9 \pm 4.1$ & $11.3 \pm 4.1$ & $19.4 \pm 7.4$ & $8.7 \pm 5.2$ & $10.0 \pm 3.8$ \\
\hline $\begin{array}{l}\text { Mean difference in } \\
\text { Schirmer wetting length } \\
\text { \& significance }\end{array}$ & $p=0.394$ & & $p=0.005$ & & $\begin{array}{l}1.3 \mathrm{~mm} \pm 2 . \\
p=0.171\end{array}$ & \\
\hline $\begin{array}{l}\text { Percentage change in } \\
\text { Schirmer wetting length }\end{array}$ & $\begin{array}{l}\text { Eye } 1 \text { unan } \\
\text { vs. Eye } 1 \text { an } \\
\text { Eye } 2 \text { unan } \\
\text { vs. Eye } 2 \text { an }\end{array}$ & $\begin{array}{l}\text { ised } 23.1 \pm 7.2 \\
\text { tised } 8.7 \pm 5.2 \\
\text { ised } 24.9 \pm 4.1 \\
\text { tised } 10.0 \pm 3.8\end{array}$ & $62.4 \%$ & & Average & $61.1 \%$ \\
\hline
\end{tabular}


TABLE 2. Summary of studies

\begin{tabular}{|c|c|c|c|c|c|}
\hline Measure & Subjects & $\mathbf{n}$ & Findings & $\begin{array}{l}\% \\
\text { change }\end{array}$ & Authors \\
\hline \multicolumn{6}{|c|}{ Schirmer test: $\mathrm{mm}$ in $\mathbf{5}$ minutes } \\
\hline $\begin{array}{l}\text { Unanaesthetised and } \\
\text { anaesthetised Schirmer }\end{array}$ & - Normal patients & $\begin{array}{l}n=223 \\
(N)\end{array}$ & $\begin{array}{l}\text { Unanaesthetised Schirmer } 19.6 \pm 9.2 \text { vs. } \\
\text { Anaesthetised Schirmer } 11.9 \pm 7.8\end{array}$ & $39.3 \%$ & $\begin{array}{l}\text { Lamberts et } \\
\mathrm{al}^{29}\end{array}$ \\
\hline $\begin{array}{l}\text { Unanaesthetised and } \\
\text { anaesthetised Schirmer }\end{array}$ & $\begin{array}{l}\text { - Young patients ( } 25-45 \text { years) } \\
\text { - Old patients (57-71 years) }\end{array}$ & $\begin{array}{l}n=15 \\
(N)\end{array}$ & $\begin{array}{l}\text { Young, unanaesthetised Schirmer } 30 \pm 6 \text { vs. } \\
\text { Young, anaesthetised Schirmer } 14 \pm 6 \\
\text { Old, unanaesthetised Schirmer } 17 \pm 12 \text { vs. } \\
\text { Old, anaesthetised Schirmer } 9 \pm 6\end{array}$ & $\begin{array}{l}53 \% \\
47 \%\end{array}$ & $\begin{array}{l}\text { Jordan and } \\
\text { Baum }\end{array}$ \\
\hline Unanaesthetised Schirmer & $\begin{array}{l}\text { - Affected and unaffected eyes } \\
\quad \text { of NK patients } \\
\text { - HZO patients } \\
\text { - Normal controls }\end{array}$ & $\begin{array}{l}\mathrm{n}=19(\mathrm{NK}=5 \\
\mathrm{HZO}=4 \\
\mathrm{~N}=10)\end{array}$ & $\begin{array}{l}\text { NK } 2.60 \pm 3.29 \text { vs. Fellow } 11.2 \pm 6.57 \\
\text { NK } 2.60 \pm 3.29 \text { vs. HZO } 30.75 \pm 7.22 \\
\text { NK } 2.60 \pm 3.29 \text { vs. Normal } 28.5 \pm 8.03 \\
\text { Fellow } 11.2 \pm 6.57 \text { vs. Normal } 28.5 \pm 8.03\end{array}$ & $\begin{array}{l}76.8 \% \\
91.5 \% \\
90.8 \% \\
60.7 \%\end{array}$ & $\begin{array}{l}\text { Heigle and } \\
\text { Pflugfelder }\end{array}$ \\
\hline $\begin{array}{l}\text { Unanaesthetised Schirmer } \\
\text { following anaesthesia of } R \\
\text { nasal mucosa }\end{array}$ & - Normal patients & $\begin{array}{l}n=12 \\
(N)\end{array}$ & $\begin{array}{l}\text { Baseline } 23.71 \mathrm{~mm} \text { vs. Ipsilateral eye } 15.09 \mathrm{~mm} \\
\text { Baseline } 22.69 \mathrm{~mm} \text { vs. Contralateral eye } 15.95 \mathrm{~mm} \\
\text { Saline } 22.91 \mathrm{~mm} \text { vs. Ipsilateral eye } 15.09 \mathrm{~mm} \\
\text { Saline } 19.36 \mathrm{~mm} \text { vs. Contralateral eye } 15.95 \mathrm{~mm}\end{array}$ & $\begin{array}{l}36.4 \% \\
29.7 \% \\
34.1 \% \\
17.6 \%\end{array}$ & Gupta et al ${ }^{5}$ \\
\hline Unanaesthetised Schirmer & $\begin{array}{l}\text { - PRK eye } \\
\text { - Unoperated fellow eye }\end{array}$ & $\begin{array}{l}\mathrm{n}=32 \\
\text { (PRK) }\end{array}$ & PRK eye $14.45 \pm 7.79$ vs. Unoperated eye $28.33 \pm 5.89$ & $49 \%$ & $\begin{array}{l}\text { Ozdamar et } \\
\mathrm{al}^{23}\end{array}$ \\
\hline Unanaesthetised Schirmer & $\begin{array}{l}\text { - LASIK eye post-op* } \\
\text { - Unoperated fellow eye }\end{array}$ & $\begin{array}{l}n=28 \\
\text { (LASIK) }\end{array}$ & LASIK eye $16.17 \pm 2.50$ vs. Unoperated eye $21.07 \pm 7.08$ & $23.26 \%$ & Aras et $\mathrm{a}^{24}$ \\
\hline Unanaesthetised Schirmer & $\begin{array}{l}\text { - LASIK patients pre-op and } 1 \mathrm{~m} \\
\text { post-op }\end{array}$ & $\begin{array}{l}\mathrm{n}=48 \\
\text { (LASIK) }\end{array}$ & Pre-op $23.95 \pm 10.05$ vs. $1 \mathrm{~m}$ post-op $18.06 \pm 10.42$ & $24.6 \%$ & Battat et a $\left.\right|^{60}$ \\
\hline Unanaesthetised Schirmer & $\begin{array}{l}\text { - LASIK patients pre-op and } \\
1 \mathrm{~m}, 3 \mathrm{~m} \text { and } 6 \mathrm{~m} \text { post-op }\end{array}$ & $\begin{array}{l}n=42 \\
\text { (LASIK) }\end{array}$ & $\begin{array}{l}\text { Pre-op } 16.2 \pm 4.69 \text { vs. } 1 \mathrm{~m} \text { post-op } 12.8 \pm 3.15 \\
\text { Pre-op } 16.2 \pm 4.69 \text { vs. } 3 \mathrm{~m} \text { post-op } 15.25 \pm 4.2 \\
\text { Pre-op } 16.2 \pm 4.69 \text { vs. } 6 \mathrm{~m} \text { post-op } 15.96 \pm 1.2\end{array}$ & $\begin{array}{l}21 \% \\
5.9 \% \\
1.5 \%\end{array}$ & Siganos et al ${ }^{25}$ \\
\hline vs. Anaesthetised Schirmer & & & $\begin{array}{l}\text { Pre-op unanaesthetised } 16.2 \pm 4.69 \text { vs. } \\
\text { Pre-op anaesthetised } 11.6 \pm 3.45\end{array}$ & $28.4 \%$ & \\
\hline $\begin{array}{l}\text { Unanaesthetised and } \\
\text { anaesthetised Schirmer }\end{array}$ & - LASIK patients pre-op & $\begin{array}{l}\mathrm{n}=18 \\
\text { (pre-LASIK) }\end{array}$ & $\begin{array}{l}\text { Unanaesthetised } 24.53 \pm 3.34 \text { vs. } \\
\text { anaesthetised } 15.57 \pm 1.76\end{array}$ & $36.5 \%$ & Konomi et $\mathrm{a}^{32}$ \\
\hline Unanaesthetised Schirmer & $\begin{array}{l}\text { - HSK affected eye } \\
\text { - HSK unaffected fellow eye } \\
\text { - Normal controls }\end{array}$ & $\begin{array}{l}n=24 \\
\text { (HSK) }\end{array}$ & $\begin{array}{l}\text { HSK affected } 12.2 \pm 9.9 \text { vs. Control } 19.1 \pm 10.2 \\
\text { HSK Unaffected eye } 12.8 \pm 8.4 \text { vs. Control } 18.5 \pm 10.6\end{array}$ & $\begin{array}{l}36.1 \% \\
30.8 \%\end{array}$ & $\begin{array}{l}\text { Simard-Lebrun } \\
\text { et } \mathrm{al}^{17}\end{array}$ \\
\hline $\begin{array}{l}\text { Unanaesthetised and } \\
\text { anaesthetised Schirmer }\end{array}$ & $\begin{array}{l}\text { - } A D D E \\
\text { - } E D E\end{array}$ & $\begin{array}{l}\text { Dry Eye } \\
n=110 \\
(A D D E=68 \\
E D E=42)\end{array}$ & $\begin{array}{l}\text { ADDE unanaesthetised } 5 \mathrm{~mm}^{*} \text { vs. } \\
\text { ADDE anaesthetised } 3 \mathrm{~mm} * \\
\text { EDE unanaesthetised } 14 \mathrm{~mm} * \text { vs. } \\
\text { EDE anaesthetised } 6 \mathrm{~mm}^{*}\end{array}$ & $40 \% *$ & Li et al ${ }^{31}$ \\
\hline Unanaesthetised Schirmer & $\begin{array}{l}\text { - HSK affected eye } \\
\text { - HSK unaffected fellow eye } \\
\text { - Normal controls }\end{array}$ & $\begin{array}{l}n=35 \\
\text { (HSK) }\end{array}$ & $\begin{array}{l}\text { HSK affected } 15.9 \pm 3.1 \text { vs. Control } 20.3 \pm 1.8 \\
\text { HSK Unaffected eye } 17.3 \pm 2.9 \text { vs. Control } 20.8 \pm 1.7\end{array}$ & $\begin{array}{l}21.7 \% \\
16.8 \%\end{array}$ & $\begin{array}{l}\text { M'Garrech et } \\
\mathrm{al}^{18}\end{array}$ \\
\hline Unanaesthetised Schirmer & $\begin{array}{l}\text { - LASIK patients pre-op and } \\
1 \mathrm{w}, 1 \mathrm{~m} \text { and } 3 \mathrm{~m} \text { post-op }\end{array}$ & $\begin{array}{l}n=32 \\
\text { (LASIK) }\end{array}$ & $\begin{array}{l}\text { Pre-op } 13 \mathrm{~mm} * \text { vs. } 1 \mathrm{w} \text { post-op } 9 \mathrm{~mm} * \\
\text { Pre-op } 13 \mathrm{~mm} * \text { vs. } 1 \mathrm{~m} \text { post-op } 9^{*} \\
\text { Pre-op } 13 \mathrm{~mm} * \text { vs. } 6 \mathrm{~m} \text { post-op } 10^{*}\end{array}$ & $\begin{array}{l}30.7 \% \\
30.7 \% \\
23.1 \%\end{array}$ & Gao et $\mathrm{al}^{26}$ \\
\hline $\begin{array}{l}\text { Unanaesthetised and } \\
\text { anaesthetised Schirmer }\end{array}$ & - Normal patients & $\begin{array}{l}n=8 \\
(N)\end{array}$ & $\begin{array}{l}\text { Eye } 1 \text { unanaesthetised } 23.13 \pm 7.22 \text { vs. } \\
\text { Eye } 1 \text { anaesthetised } 8.69 \pm 5.20 \\
\text { Eye } 2 \text { unanaesthetised } 24.88 \pm 4.12 \text { vs. } \\
\text { Eye } 2 \text { anaesthetised } 10.00 \pm 3.78\end{array}$ & $62.4 \%$ & Current study \\
\hline \multicolumn{6}{|c|}{ In Vivo Confocal Microscopy: number of nerve trunks } \\
\hline $\begin{array}{l}\text { Total number of nerve trunks } \\
\text { and branches in a coronal } \\
\text { section, } \\
(460 \times 345 \mu \mathrm{m})\end{array}$ & $\begin{array}{l}\text { - HSK affected eye } \\
\text { - HSK unaffected fellow eye } \\
\text { - Normal controls }\end{array}$ & $\begin{array}{l}n=25 \\
\text { (HSK) }\end{array}$ & $\begin{array}{l}\text { HSK affected } 5.2 \pm 4.5 \text { vs. Control } 13.1 \pm 3.8 \\
\text { HSK Unaffected eye } 7.8 \pm 3.3 \text { vs. Control } 13.1 \pm 3.8\end{array}$ & $\begin{array}{l}60.3 \% \\
40.5 \%\end{array}$ & Hamrah et al ${ }^{56}$ \\
\hline $\begin{array}{l}\text { Total number of nerve trunks } \\
\text { and branches in a coronal } \\
\text { section } \\
(460 \times 345 \mu \mathrm{m})\end{array}$ & $\begin{array}{l}\text { - HZO affected eye } \\
\text { - HZO unaffected fellow eye } \\
\text { - Normal controls }\end{array}$ & $\begin{array}{l}n=27 \\
(H Z O)\end{array}$ & $\begin{array}{l}\text { HZO affected } 5.4 \pm 2.8 \text { vs. Control } 13.1 \pm 3.8 \\
\text { HSK Unaffected fellow } 8.3 \pm 2.9 \text { vs. Control } 13.1 \pm 3.8\end{array}$ & $\begin{array}{l}58.8 \% \\
36.6 \%\end{array}$ & Hamrah et al ${ }^{57}$ \\
\hline \multicolumn{6}{|c|}{ Fluorophotometry: tear turnover \%/minute } \\
\hline $\begin{array}{l}\text { Fluorophotometry with and } \\
\text { without anaesthesia }\end{array}$ & $\begin{array}{l}\text { - Young patients ( } 25-45 \text { years) } \\
\text { - Old patients (57-71 years) }\end{array}$ & $\begin{array}{l}n=15 \\
(N)\end{array}$ & $\begin{array}{l}\text { Young, unanaesthetised } 0.9 \pm 0.4 \text { vs. } \\
\text { Young, anaesthetised } 0.2 \pm 0.1 \\
\text { Old, unanaesthetised } 0.9 \pm 0.2 \text { vs. } \\
\text { Old, anaesthetised } 0.4 \pm 0.2\end{array}$ & $\begin{array}{l}77 \% \\
55 \%\end{array}$ & $\begin{array}{l}\text { Jordan and } \\
\text { Baum } \\
30\end{array}$ \\
\hline $\begin{array}{l}\text { Fluorophotometry without } \\
\text { anaesthesia }\end{array}$ & $\begin{array}{l}\text { - HSK affected eye } \\
\text { - HSK unaffected fellow eye } \\
\text { - Normal controls }\end{array}$ & $\begin{array}{l}\mathrm{n}=16 \\
\text { (HSK) }\end{array}$ & $\begin{array}{l}\text { HSK affected } 7.9 \pm 4.9 \text { vs. Control } 14.3 \pm 6.5 \\
\text { HSK unaffected fellow } 7.9 \pm 5.6 \text { vs. Control } 14.3 \pm 6.5 \\
\text { HSK affected } 7.9 \pm 4.9 \text { vs. HSK unaffected eye } 7.9 \pm 5.6\end{array}$ & $\begin{array}{l}44.8 \% \\
44.8 \% \\
0 \%\end{array}$ & Keijser et al ${ }^{55}$ \\
\hline \multicolumn{6}{|c|}{ Central corneal sensitivity: $\mathbf{m m}$} \\
\hline Cochet-Bonnet & $\begin{array}{l}\text { - LASIK patients pre-op and } 1 \mathrm{w} \text {, } \\
1 \mathrm{~m} \text { and } 3 \mathrm{~m} \text { post-op } \\
\text { - ReLEx patients pre-op and } 1 \mathrm{w} \text {, } \\
1 \mathrm{~m} \text { and } 3 \mathrm{~m} \text { post-op }\end{array}$ & $\begin{array}{l}\mathrm{n}=47 \\
(\mathrm{LASIK}=32 \\
\text { ReLEx }=15)\end{array}$ & 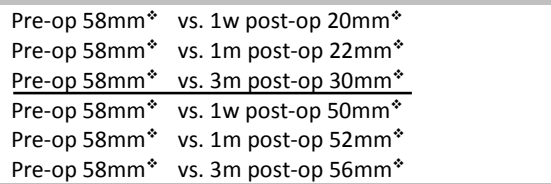 & $\begin{array}{l}65.5 \% \\
62.1 \% \\
48.3 \% \\
13.8 \% \\
10.3 \% \\
3.4 \%\end{array}$ & Gao et $\mathrm{al}^{26}$ \\
\hline Cochet-Bonnet & $\begin{array}{l}\text { - LASIK patients pre-op and } 1 \mathrm{w} \text {, } \\
1 \mathrm{~m} \text { and } 6 \mathrm{~m} \text { post-op }\end{array}$ & $n=48$ & $\begin{array}{l}\text { Pre-op } 36 \mathrm{~mm}^{*} \\
\text { Pre-op } 36 \mathrm{~mm}^{*}\end{array}$ & $\begin{array}{l}91.7 \% \\
50.0 \% \\
66.7 \%\end{array}$ & Battat et al ${ }^{60}$ \\
\hline \multicolumn{6}{|c|}{ Central corneal sensitivity: $\mathrm{gm} / \mathrm{cm}^{2}$} \\
\hline Cochet-Bonnet & $\begin{array}{l}\text { - LASIK patients pre-op and } 1 \mathrm{w} \text {, } \\
3 \mathrm{~m} \text { and } 9 \mathrm{~m} \text { post-op }\end{array}$ & $n=24$ & $\begin{array}{ll}\text { Pre-op } 1 \mathrm{gm} / \mathrm{cm}^{2 *} & \text { vs. } 1 \mathrm{w} \text { post-op } 2.3 \mathrm{gm} / \mathrm{cm}^{2 *} \\
\text { Pre-op } 1 \mathrm{gm} / \mathrm{cm}^{2 *} & \text { vs. } 3 \mathrm{~m} \text { post-op } 1.5 \mathrm{gm} / \mathrm{cm}^{2 *} \\
\text { Pre-op } 1 \mathrm{gm} / \mathrm{cm}^{2 *} & \text { vs. } 9 \mathrm{~m} \text { post-op } 1 \mathrm{gm} / \mathrm{cm}^{2 *}\end{array}$ & $\begin{array}{l}56.5 \% \\
33.3 \% \\
0.0 \%\end{array}$ & Konomi et al ${ }^{32}$ \\
\hline
\end{tabular}

$\mathrm{ADDE}=$ aqueous deficient dry eye; $\mathrm{EDE}=\mathrm{evaporative} \mathrm{deficient} \mathrm{dry} \mathrm{eye;} \mathrm{HSK=Herpes} \mathrm{simplex} \mathrm{keratitis;} \mathrm{HZO}=$ Herpes zoster ophthalmicus; LASIK=Laser-Assisted In-Situ Keratomileusis; N=normal; NK=neurotrophic keratitis; PRK=photorefractive keratectomy; ReLEx=Refractive Lenticule Extraction *Approximate from figures; * Timescale of test not stated 
Visit 1

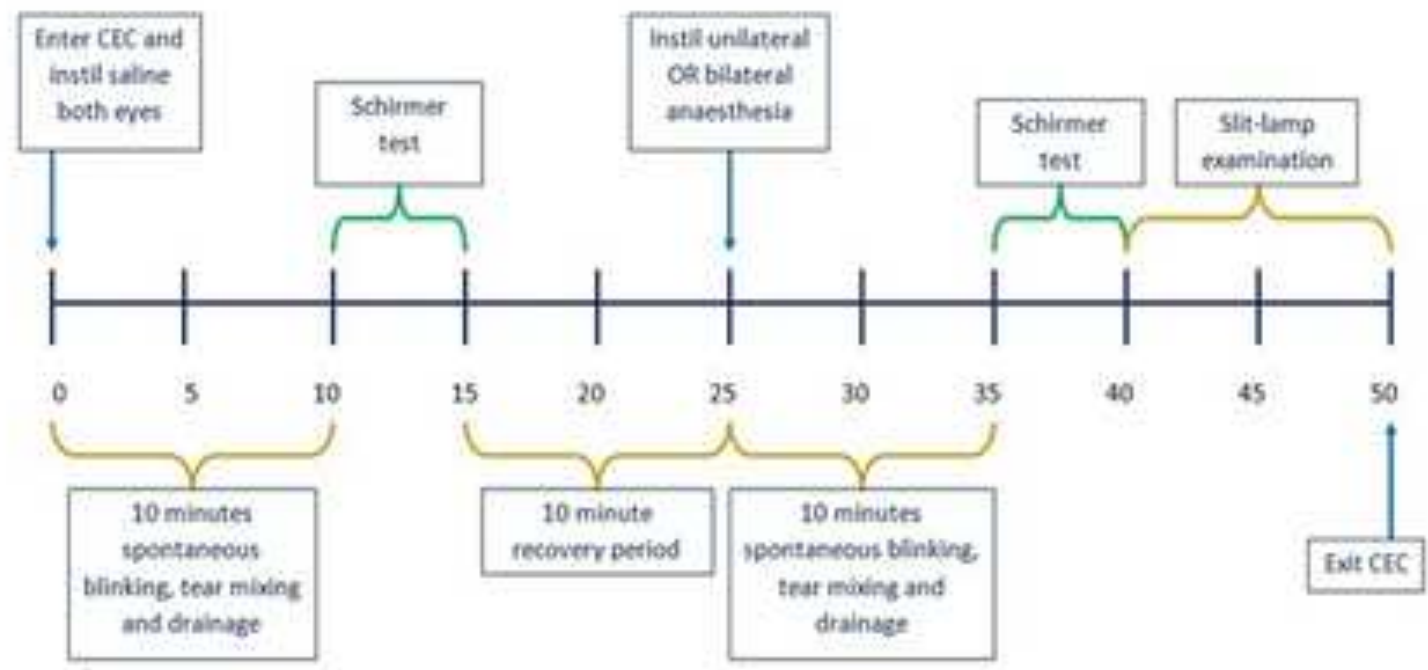

Minutes $\rightarrow$

\section{Visit 2}

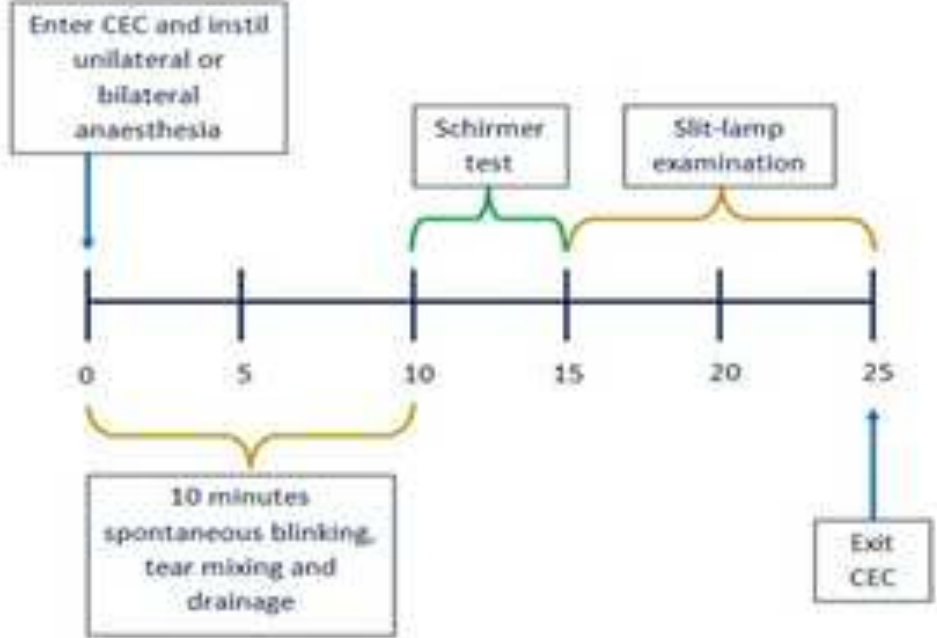

Minutes $\rightarrow$ 
Click here to download Figure LFU2_cornea2017.tif $\underline{\underline{\underline{ }}}$

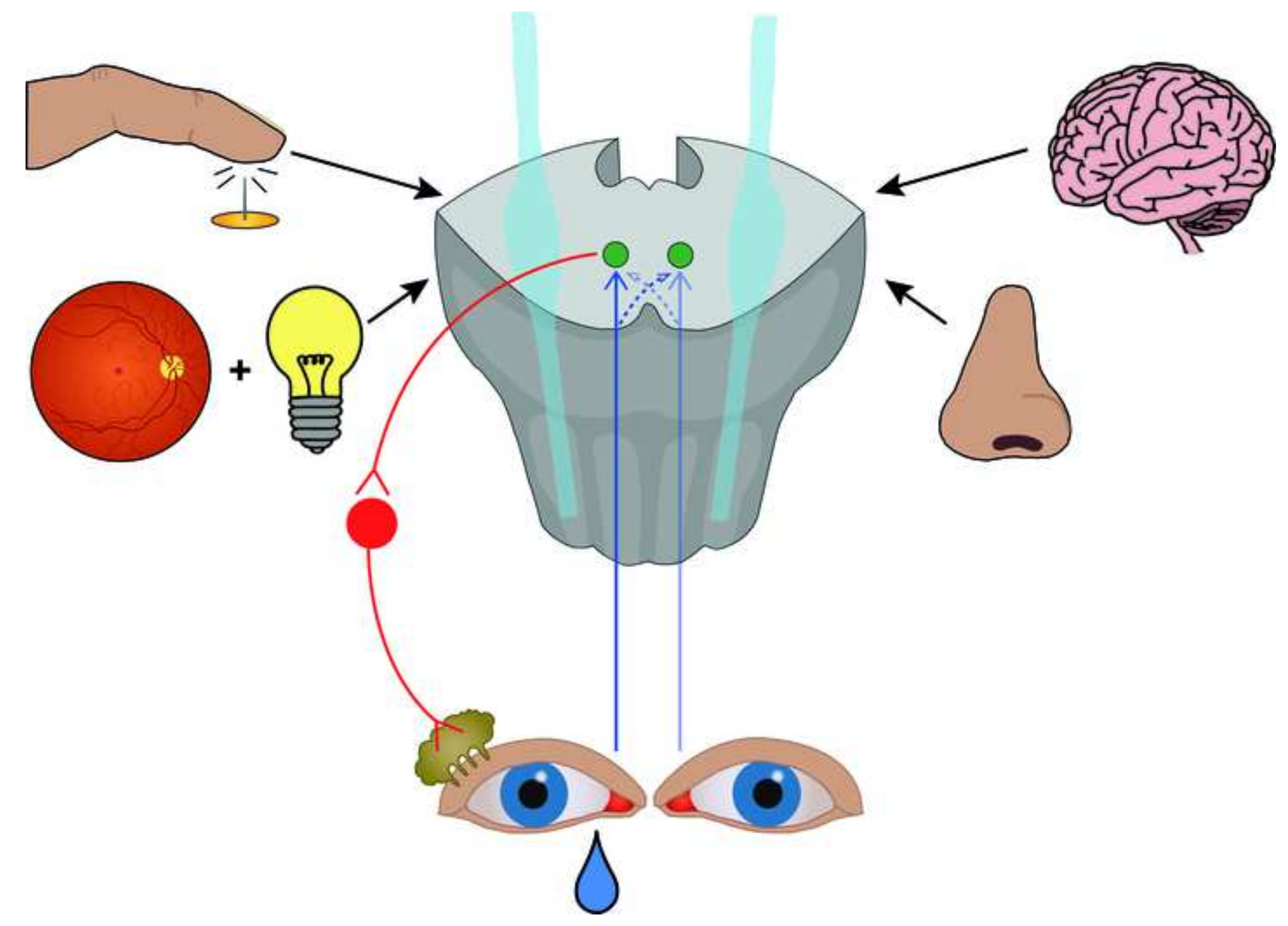



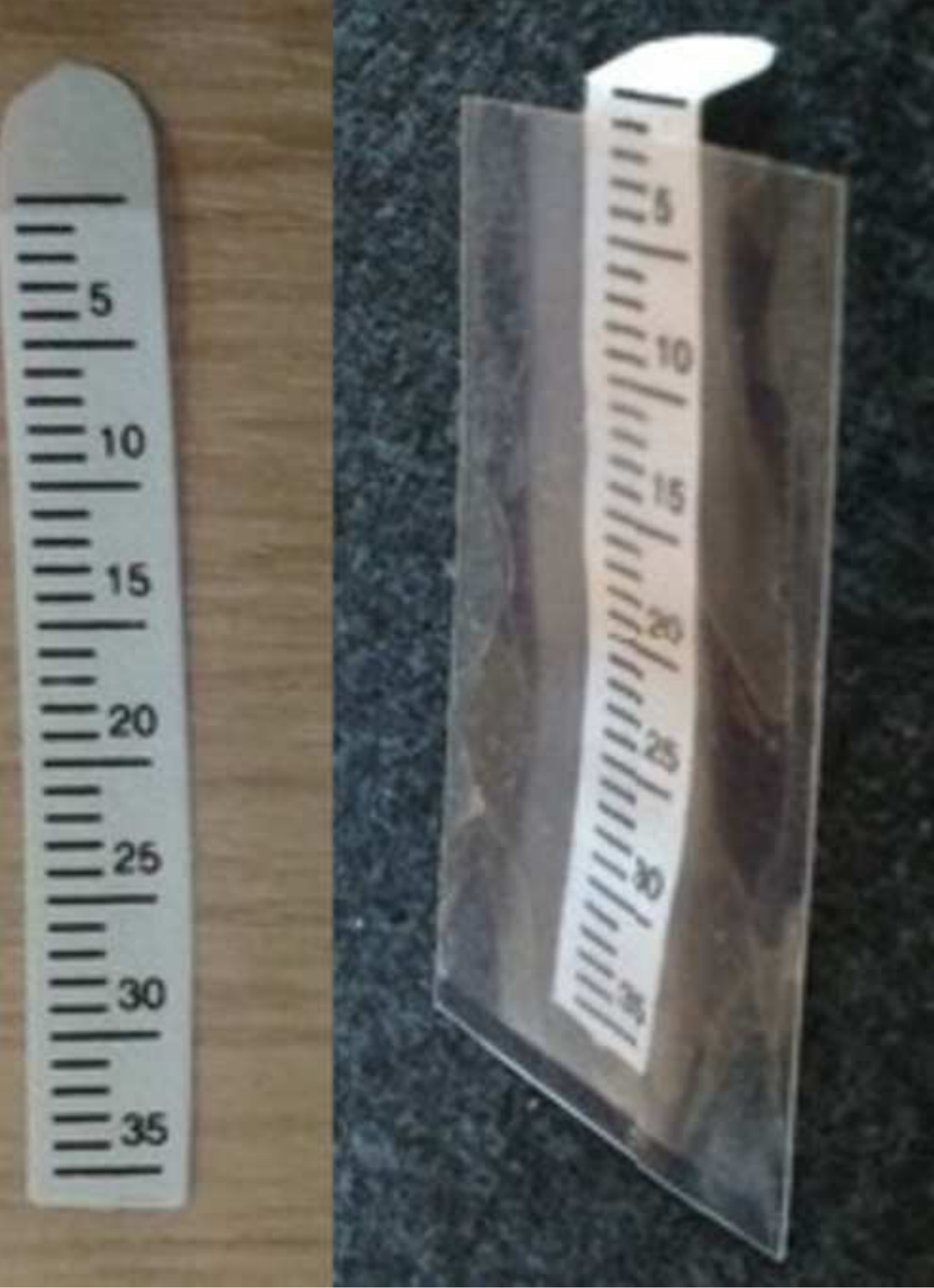

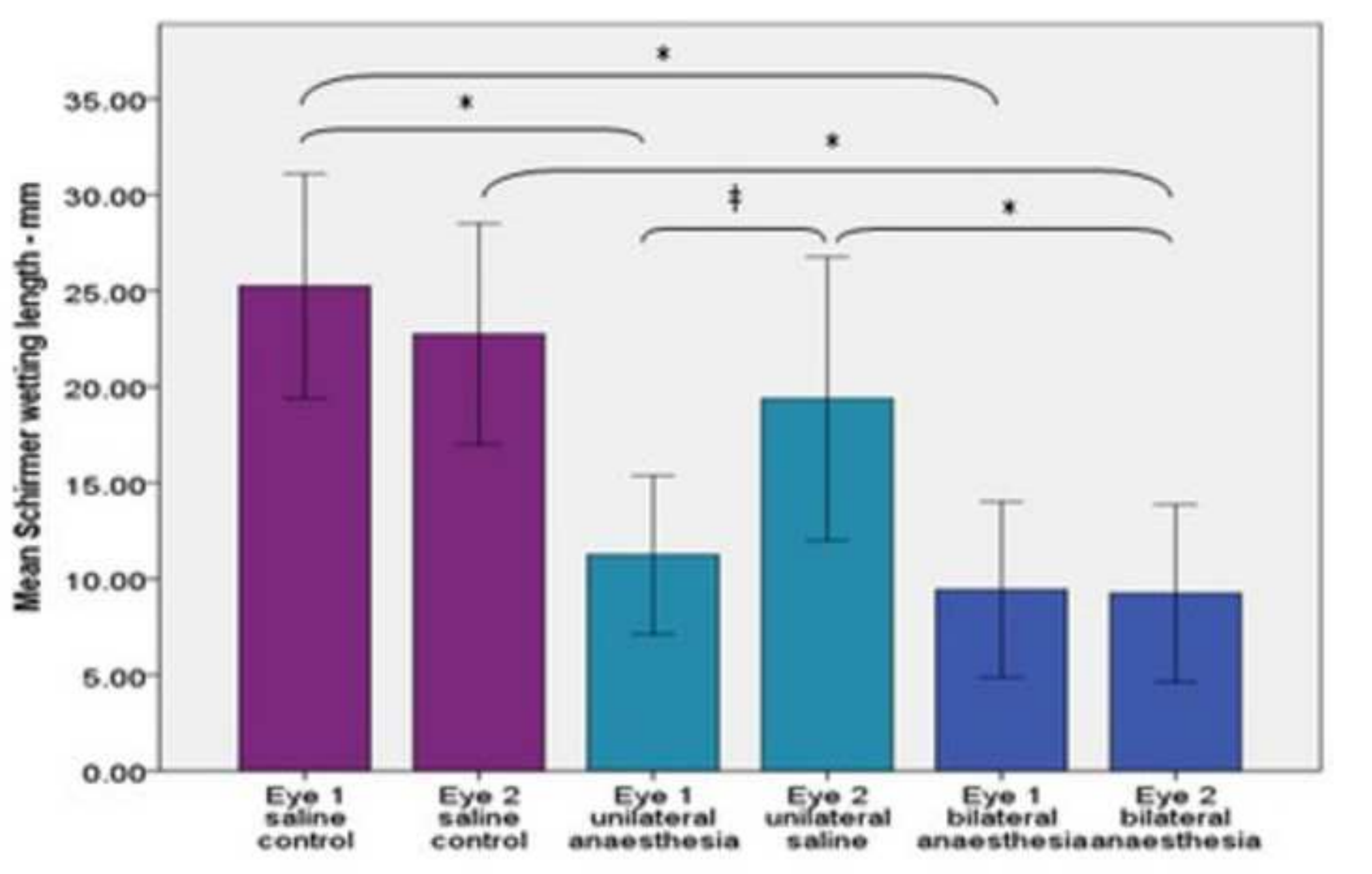

(1)

\begin{abstract}
control control
\end{abstract}

